\title{
ENTREVISTA COM A PROFESSORA MARIA CRISTINA BATALHA ACERCA DA LITERATURA IISSOLLITA EM LIINGUA PORTUGUESA
}

http://dx.doi.org/10.11606/issn.2175-3180.v13i24p252-256*

Por Bruno Anselmi Matangrano ${ }^{\mathrm{I}}$

Maria Cristina Batalha é professora associada da Universidade do Estado do Rio de Janeiro - UERJ, onde atua na Graduação e PósGraduação. É mestra em Literaturas de Língua Portuguesa pela PUC-RJ (1992) e Doutora em Literatura Comparada pela Universidade Federal Fluminense - UFF (2003). Atualmente desenvolve o projeto "Cânones: literatura maior, literatura menor", onde pesquisa a literatura fantástica, o romantismo e ultrarromantismo nos contextos brasileiro, português e francês. Sua pesquisa contempla também a manifestação do insólito nas literaturas lusófonas e francófonas. É membro do GT da ANPOLL "Vertentes do insólito ficcional", do Grupo de Pesquisa do CNPq "Nós do insólito: vertentes da ficção, da teoria e da crítica", da UERJ, e do Grupo de Pesquisa "Vertentes do fantástico na literatura", da UNESP. Tem livros, capítulos de livros, artigos e ensaios publicados em periódicos nacionais e internacionais.

\footnotetext{
* Publicada originalmente na revista Desassossego, v. 6, n. 11, jun/2014: https://www.revistas.usp.br/desassossego/issue/view/6361

DOI original: http://dx.doi.org/10.11606/issn.2175-3180.v6i11p188-192

I Universidade de São Paulo, São Paulo, Brasil.
} 
BRUNO ANSELMI MATANGRANO: Professora Maria Cristina, para começar, queria que falasse um pouco de sua experiência com a Literatura Fantástica em língua portuguesa e quais as dificuldades e desafios de se trabalhar com o Fantástico no Brasil?

MARIA CRISTINA BATALHA: Meu interesse surgiu a partir da pesquisa que realizei para o Doutorado, quando trabalhei a literatura fantástica como uma encenação da modernidade. Nessa Tese, mostro que o fantástico, em seu sentido estrito, nasce em finais do século XVIII, com a novela O diabo enamorado (1772), de Jacques Cazotte. Ele aparece como uma variante do maravilhoso e reflete as aporias advindas de uma mudança de mentalidade, que põe em confronto uma visão racionalista do mundo e a permanência de crenças arraigadas, que as ciências não conseguem explicar. Apesar de ter nascido na França, o fantástico só encontra sua plena expressão, sua complexidade e se fixa como modelo genérico, com os contistas alemães, sobretudo com Hoffmann. Em um primeiro momento, fazia parte do projeto estender os estudos até a literatura fantástica no Brasil. Com o excesso de material sobre os primórdios do gênero, as condições de seu nascimento, sua evolução etc., ficou inviabilizada a proposta inicial que só foi retomada em uma segunda fase, em projeto posterior.

BAM: A senhora acha que ainda há preconceito com quem pesquisa literatura Fantástica, ou Insólita? Se sim, acha que esse preconceito é maior no Brasil?

$M C B$ : Existiu esse preconceito no período que os críticos denominam o da "formação" da literatura brasileira, ou seja, no século XIX. Havia então um compromisso dos escritores em apresentar o Brasil, descrevê-lo, fixar nossas origens e marcar nossa diferença. Imperou assim a vocação documental e realista da literatura brasileira, descartando uma outra leitura da realidade que não tivesse esse perfil. Isso explica a pouca produção da literatura fantástica, embora isso nem sempre signifique falta de qualidade. Hoje, há uma alteração completa desse quadro e a produção fantástica ganha um espaço bem maior, acompanhando uma tendência mais geral, seguindo a trilha aberta pelo boom do realismo maravilhoso latino-americano, iniciado nos anos 40, e que chega ao apogeu nos anos 60, projetando a literatura sul americana no mundointeiro. 
Nos países que estavam empenhados em construir uma literatura nacional, vinculada a um projeto realista, em particular no Brasil, em Portugal e na própria França, a produção fantástica chegou bem mais tarde, teve um espaço bem mais restrito e somente agora ganha o reconhecimento da crítica e das academias.

BAM: Tive a oportunidade de ler seu livro O Fantástico Brasileiro: Contos Esquecidos e de fato encontrei ali textos sobre os quais nunca ouvira falar. Gostaria que nos contasse um pouco sobre esse trabalho de resgate das origens do fantástico em língua portuguesa.

MCB: No início da coleta do material para reunir contos fantásticos brasileiros, fiquei presa à conceituação de fantástico todoroviana. Com isso, fui descartando muitos textos de surpreendente interesse e originalidade por não entrarem no modelo de um fantástico mais estrito, baseado na hesitação do leitor. Hoje, com o recuo do tempo e o avanço das pesquisas, tenho uma concepção muito mais aberta do conceito de fantástico e o considero como um macro-gênero, ou um gênero que pode comportar muitos sub- gêneros que têm o insólito como ponto em comum. Essa foi então a orientação teórica que conduziu a pesquisa.

Quanto ao critério de organização, procurei deixar de lado os autores já tradicionalmente identificados pela historiografia literária brasileira como autores de literatura fantástica. Também busquei afastar o critério de "melhores contos", já que meu objetivo era trazer à tona autores e obras "esquecidas".

Para fazer o levantamento desses textos, parti de antologias de contos organizadas anteriormente por autores como Jerônimo Monteiro (1959), Jacob Penteado (1961) e, mais recentemente, as de Braulio Tavares (2003) e Flávio Moreira da Costa (2002). Essas antologias me deram pistas de onde procurar mais além. Por outro lado, também percorri outras coletâneas de contos que não tinham rótulo de "fantástico", mas sim de "contos regionalistas", "contos de mistério", "contos de terror" etc. Deparei-me com autores inusitados que, embora consagrados pela crítica como representantes de outras estéticas, também tinham uma parte de sua produção ligada ao fantástico. Esse percurso me levou a muitos nomes completamente esquecidos pela historiografia literária e que, hoje, são objeto de vários estudos acadêmicos. 
Do ponto de vista prático, tive que me ater a um período que não avançasse muito pelo século $X X$, por razões de direitos autorais. Também, como expliquei anteriormente, fixada no modelo genérico proposto por Todorov, deixei escapar muitos outros contos que poderiam perfeitamente integrar a antologia. Se tivesse que organizar uma outra antologia, faria muita coisa de modo diferente, a começar pela revisão dos conceitos de fantástico, maravilhoso, insólito, animismo, realismo mágico etc. Como meu intuito não era de definir ou redefinir o gênero, poderia ter reunido muitos outros contos brasileiros "esquecidos". Quando você se fixa em um modelo teórico muito fechado, fica frustrado com textos que escapam a esse modelo; e eles sempre escapam...

BAM: Dando continuidade à pergunta anterior, a senhora acha que a produção de literatura fantástica em língua portuguesa é menor do que em outros países ou simplesmente muito dessa produção foi negligenciada pela nossa historiografia literária?

MCB: As razões são de ordem histórica: como não era um modelo legitimado pelas academias, sua produção ficou limitada e sem visibilidade. O viés aberto pela produção ficcional de Álvares de Azevedo permaneceu um caminho quase solitário na nossa série literária e não serviu de modelo de emulação. Presa a exemplos identificados com um romantismo "lacrimoso" e sensacionalista, a ficção fantástica fica relegada a um segundo plano tanto pela crítica, como pelos próprios escritores que não querem ver seus nomes associados a ela. Daí a pouca importância em termos numéricos. Se nem todos os contos eram de grande qualidade literária, a culpa fica por conta da falta de reconhecimento. Falo isso com relação ao Brasil e a Portugal; quando surgem as primeiras manifestações das literaturas africanas de língua portuguesa, já a literatura fantástica em seu sentido amplo não constitui um tabu e já desfruta de reconhecimento no cenário literário. Nesse caso, ao contrário, o animismo e o realismo maravilhoso da maioria dessa ficção investem-se de característica hegemônica porque são traços de identificação cultural.

BAM: Por outro lado, nos últimos tempos o número de publicações voltadas a essas temáticas cresceu muito. A senhora acompanha o crescimento do gênero no Brasil e no mundo? O que diz da atual produção da Literatura Insólita de Língua Portuguesa? Há algum nome que considere promissor? 
MCB: Sim, há um interesse muito grande pela estética do fantástico (gótico, realismo mágico, insólito etc.) expressa em filmes, quadrinhos e obras literárias. Acredito que essa demanda fique por conta de um fenômeno de moda, mas também porque o fantástico desacredita e relativiza os modelos de pensamento e de representação baseados na racionalidade e no pragmatismo. O mundo não parece mais explicar-se por esse viés.

Há nomes como Tolkien, por exemplo, que são sucesso pelo mundo todo. Aqui no Brasil, temos nomes como Flávio Carneiro, Alexandre Raposo, Luiz Vilela, Rubens Figueiredo, Heloisa Seixas, Amilcar Bettega Barbosa, entre muitos outros, além dos já consagrados como Lygia Fagundes Telles e Ignácio de Loyola Brandão.

$B A M$ : Por fim, gostaria que a senhora falasse um pouco de seu trabalho com cânones. Quais são os desafios e dificuldades ao se estabelecer um cânone da literatura fantástica? Para a senhora quais seriam exemplos de "Literatura Maior" e de "Literatura Menor"?

MCB: Esses dois conceitos de "maior" e "menor" estão ligados a vários referenciais. Podem referir-se à literatura mais popular, menos "acadêmica", de baixa qualidade, como os best-sellers, à literatura dita de massa, mas também podem designar uma escolha deliberada por parte de um autor de não pertencimento ao cânone. Seria o caso dos out-siders.

Com a descentralização, o aporte das culturas periféricas, o reconhecimento de diversas manifestações literárias saídas de lugares de exclusão, fica difícil estabelecer gradações genéricas, modelos canônicos hegemônicos e altares para a consagração de autores e obras. Fica tudo sob a égide do relativo e do passageiro; talvez esse seja o novo "cânone".

\section{Licença: (9) (i) (\$)}

Concepção e realização da entrevista:

Bruno Anselmi Matangrano

Doutor e mestre egresso do Programa de Pós-Graduação em Literatura Portuguesa da Universidade de São Paulo (USP).

Contato: bamatangrano@yahoo.com.br

(iD : https://orcid.org/0000-0001-7914-0804 